\title{
Mushroom Spores in the Stool Mimicking Parasite Ova
}

\author{
Tsung $\mathrm{SH}^{*}$
}

\author{
St Mary's Hospital Loudong, Yilan Taiwan
}

*Corresponding author: Tsung SH, St Mary’s Hospital Loudong, Yilan, Taiwan, Tel: 8863 954106, E-mail: tsung.sweihsiung@gmail.com

Citation: Tsung SH (2017) Mushroom Spores in the Stool Mimicking Parasite Ova. J Gastroenterol Metabol 1: 101 Article history: Received: 16 October 2017, Accepted: 16 November 2017, Published: 17 November 2017

\begin{abstract}
The mushroom Agaricus blazei Murill from the Brazilian has been used as health food for the prevention of a range of diseases, including infection, allergy, and cancer. In this brief communication, I wish to share the experience that I found the parasite like spores in the stool after eating Agaricus blazei Murill.
\end{abstract}

Keywords: Mushroom; Health Food; Cancer; Parasite

List of abbreviation: ABM (Agaricus blazei Murill)

\section{Introduction}

The mushroom Agaricus blazei Murill originally from Brazilian rain forest, is rich in the immunomodulating polysaccharides, and was brought to Japan due to alleged health effects, and is widely used today in Oriental countries, mostly for the prevention of a range of diseases, including cancer, allergy, infection [1,2]. However, the biological pathways and chemical substances involved in its pharmacological activities are still not clear. Furthermore, its toxicity and side effect has not been completely and fully evaluated.

Author(s) encountered a 64-year-old male patient who had malignant lymphoma and was in remission after treatment. During his routine follow up, his physician ordered laboratory tests including stool examination. In his stool, we found numerous parasite ovum like material mimicking the eggs of Clonorchis sinensis (Figure 1). We sent the slide to Professor of parasitology, Chen YinLin at Kaohsiung Medical University for consultation. He ruled out the possibility of being the egg of Clonorchis sinensis because of its size and suggested that they might be some kind of fungal spores.

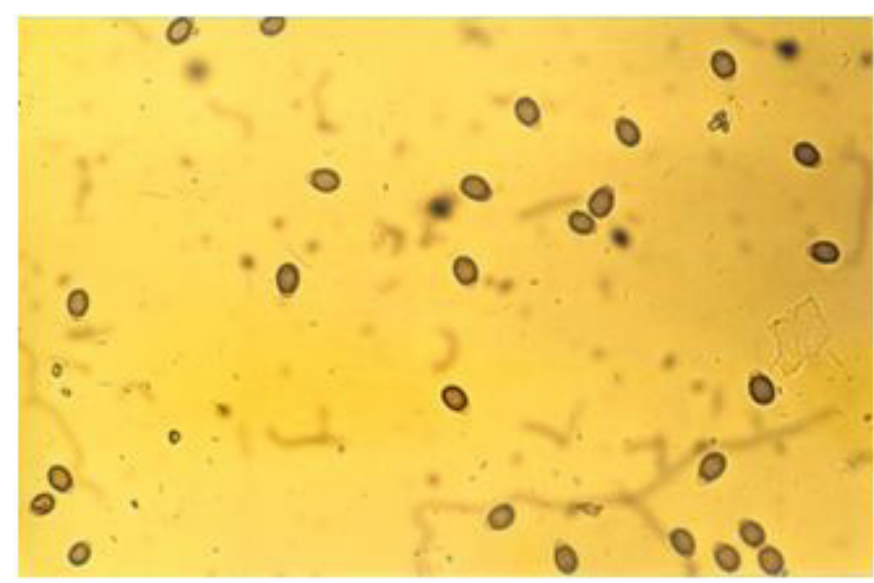

Figure 1: Fungal spores mimicking the ova of Clonorchis sinensis

Through questioning the patient, we found out that the patient was taking dry mushroom (ABM) cooked with chicken for nearly one year, in order to prevent his lymphoma from recurrence. We advised the patient to stop taking ABM as a supplement for one week and reexamined his stool, the parasite ovum like material was no longer present. Meantime, we re-examined the original slide, and the parasite ovum like material was germinating (Figure 2). We strongly felt that the parasite ovum like material was from eating $\mathrm{ABM}$. Understanding of this phenomenon may obviate unnecessary misdiagnosis. 


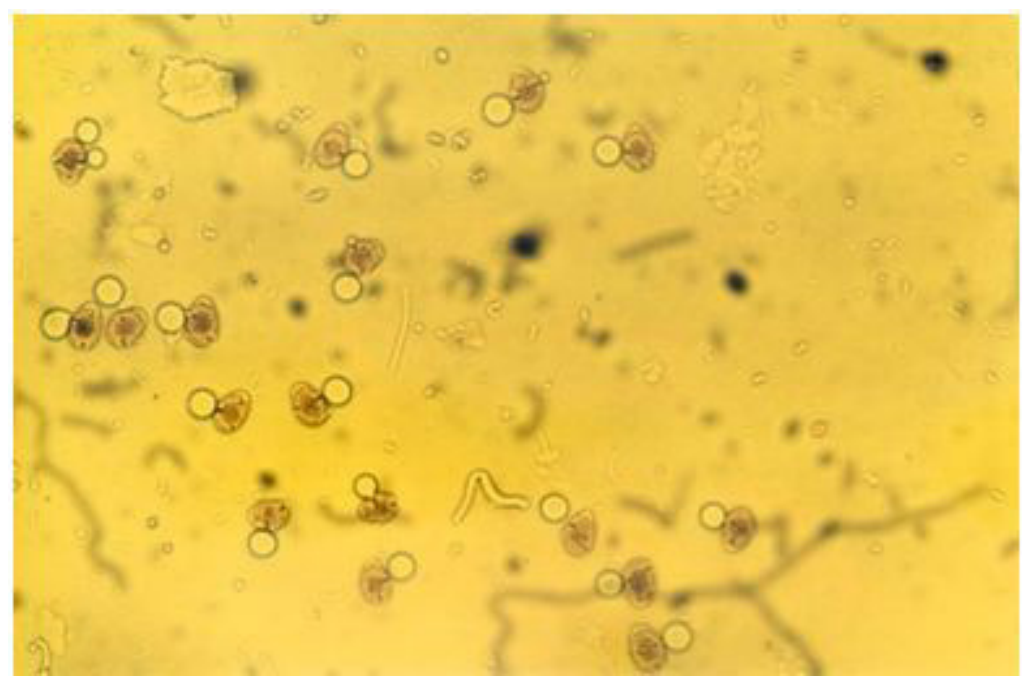

Figure 2: The parasite like ova were germinating

\section{References}

1. Firenzuoli F, Gori L, Lombardo G (2008) The medicinal mushroom Agaricus blazei Murrill. Review of literature and Phamaco-toxicological problems. Evid Based Complement Alternat Med 5: 3-15.

2. Hetland G, Johnson E, Lyberg T, Kvalheim G (2011) The mushroom Agaricus blazei Murill elicits medicinal effects on tumor, infection, allergy, and inflammation through its modulation of innate immunity and amelioration of Th1/Th2 inbalance and inflammation. Adv Pharmacol Sci 2011: 157015. 